\title{
An Application Framework for Smart Education System Based on Mobile and Cloud Systems
}

\author{
Toru KOBAYASHI $^{\dagger \text { a) }}$, Senior Member, Kenichi ARAI ${ }^{\dagger}$, Member , Hiroyuki SATO ${ }^{\dagger \dagger}$, Shigeaki TANIMOTO ${ }^{\dagger \dagger}$, \\ and Atsushi KANAI ${ }^{\dagger+\dagger}$, Senior Members
}

\begin{abstract}
SUMMARY Smart education environment, that is a learning environment utilizing the Information Communication Technology (ICT), has attracted a great deal of attention. In order to expand this environment, we need a system that can establish the learning environment armed cloud systems to reduce a significant strain on teaching staff. The important issue for such system is extensibility because the system should be adapted to many kinds of original digital learning material with minimum modification. Therefore, this paper proposes "An Application Framework for Smart Education System: SES Framework". In this Smart Education System, multi-aspect information concerning to a technical term embedded in the original digital learning material can be retrieved from different social media automatically. They can be also displayed on multi-screen devices according to user's operation. It is implemented based on "Transforming Model" which enables the migration of the original digital learning material to the smart education environment. It also has an easy operation flow for trainees named "three-step selection flow". SES Framework derived from Model-View-Controller (MVC) pattern is based on the system architecture that enables triple mashup against the original digital learning material, external social media, and screen devices in front of users. All these functionalities have been implemented on cloud systems. We show SES Framework through the implementation example. We also demonstrate the effectiveness of SES Framework by indicating the system modification case study.

key words: application framework, smart education, mobile and cloud systems, service-oriented architecture, Model-View-Controller
\end{abstract}

\section{Introduction}

Education environment has faced a major revolutionary period thanks to the current Information Communication Technology (ICT) movement. One example is Moodle, the popular learning management system [1]. Moodle is a free and an open-source type software system that has been developed as an e-learning platform. Currently, Moodle helps to make education efficient at many educational institutions, mainly in universities.

A revolution has also been occurring at real learning fields, such as the classroom not only in universities but also

Manuscript received November 10, 2016.

Manuscript revised March 28, 2017.

Manuscript publicized July 21, 2017.

$\dagger$ The authors are with Nagasaki University, Nagasaki-shi, 8528521 Japan.

${ }^{\dagger}$ The author is with The University of Tokyo, Tokyo, 113-8658 Japan.

${ }^{+\dagger}$ The author is with Chiba Institute of Technology, Narashinoshi, 275-0016 Japan.

†⿰讠十 The author is with Hosei University, Koganei-shi, 184-8584 Japan.

a)E-mail: toru@ cis.nagasaki-u.ac.jp

DOI: 10.1587/transinf.2016OFP0001 in elemental schools, thanks to the expansion of the ICT. For example, Ministry of Internal Affairs and Communications (MIC), Japan, is leading the Future School Promotion Project [2]. Tablet computers have been distributed to each student at twenty elementary schools and junior high schools selected by this project. Each school has had its classrooms equipped with electronic black boards and a $\mathrm{Wi}$ $\mathrm{Fi}$ infrastructure. Field study is currently ongoing in these schools in order to evaluate the educational efficiency of using the digital learning material, in order to better develop the teaching methods and the standard learning material. We call this kind of ICT equipped classroom environment; smart education environment. The Japanese government announced that tablet computers would be distributed to all trainees by 2020. Therefore, it will be expected that smart education environment will receive more and more attention according to this Japanese government's movement on ICT investment. However, the introduction of smart education environment to real education fields will cause a major problem; increased load on teaching staff such as setting server or network environment. In order to solve this problem, we need a system that can establish the learning environment armed cloud systems. The important issue for such system is extensibility because the system should be adapted to many kinds of original digital learning material with minimum modification. We call this system Smart Education System. Therefore, the objective of our study is to establish Smart Education System that has the operability and the extensibility.

On the other hand, we had developed a system for retrieving trendy information such as hot words or SNS topics utilizing social media [3]-[5]. Hot words mean popular searching keywords on search engines. SNS topics indicate posted messages among friends of the target user. In this research, the system picks up a searching keyword from the trendy information automatically. Then, the system is gathering multi-aspect information from social media such as outline information (DBpedia), social videos (YouTube), tweets (Twitter), and books or products (Amazon). Moreover, the system distributes the multi-aspect information to a multi-screen environment. Figure 1 shows the usage scene of this system. In this system, one mobile device should be assigned as an operation device by a user like a tablet computer in Fig. 1. The other screen devices will be used for showing multi-aspect information named display device. In this system, users do not have to input search keywords 


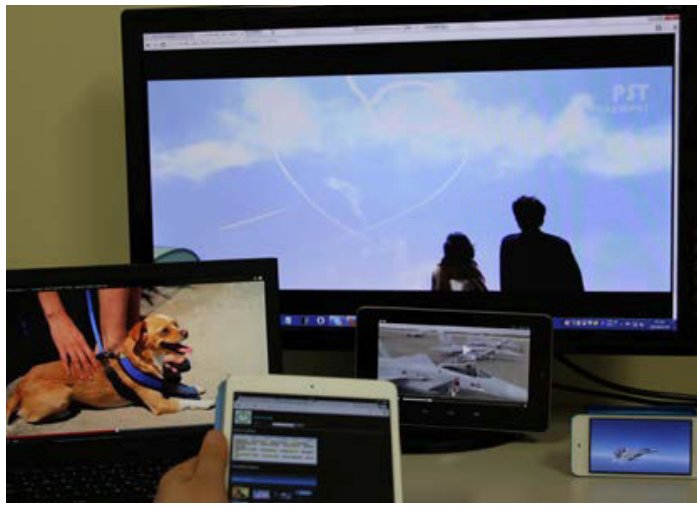

Fig. 1 Our previous multi-screen system usage scene

to find trendy information at that time. Users only have to watch and select one of the presented information items. In this way, users can retrieve the details of the desired trendy information from several kinds of aspects. Currently, users need to think about search keywords and individually input them into web services. However, in this system, users do not have to think of search keywords nor input them separately into web services. This research focused on the trendy information. However, we believe that we can realize Smart Education System based on our previous work because we can regard the trendy information as analogous to the digital learning material and the multi-screen environment as such for the smart education environment including electronic black boards. We also consider that we can reduce the load on teaching staff by introducing Smart Education System as a cloud based system.

Then, we developed MSaas-type (Mobile Software as a service-type) Smart Education System that we regarded trendy information as analogous to the digital learning material for liberal arts education [6]. In this study, we confirmed that we could provide the smart education environment in the real education field and we only needed browserinstalled devices in the real education field. However, in order to extend our previous work to Smart Education System that can be used for many kinds of learning subjects, we need to change the target information from the trendy information to the digital learning material. We also need to make clear an application framework to improve system extensibility. Therefore, we propose "An Application Framework for Smart Education System: SES Framework" [7] that targets Wikibooks [8] as the original digital learning material. Wikibooks is the open-content textbooks collection that anyone can access via HTTP, so that we considered that it would be suitable digital learning material as our first implementation target.

Smart Education System we defined focuses on a technical term embedded in the original digital learning material. The multi-aspect information will be gathered from social media using a technical term. Then, the gathered multiaspect information would be distributed on the smart education environment, covering mobile devices and multi-screen
ICT devices. In this way, if we can extract only the technical term from the original digital learning material such as Wikibooks, we can transform the original digital learning material into one for the smart education environment automatically. We defined this mechanism as Transforming Model. We also defined three-step selection flow that enables trainees to see multi-aspect information utilizing social media concerning the chosen technical term.

SES Framework derived from Model-View-Controller (MVC) pattern is based on a system architecture that enables three kinds of combinations, we call it triple mashup, against the original digital learning material, external social media, and screen devices in front of users. We constructed a prototype system as an implementation example based on SES Framework on a cloud service environment. We show SES Framework through the implementation example that targets Wikibooks. We also demonstrate the effectiveness of SES Framework by indicating the system modification case study that changes the target digital learning material from Wikibooks to news articles.

\section{Related Work}

Here we will focus on the cloud based Smart Education System that can be used for helping trainees to understand unknown technical terms utilizing social media. Therefore, we pick up the related work about e-learning services utilizing cloud computing and the unknown term learning support system.

Many cloud based e-learning services [9]-[12] have been proposed. Most of these related systems focus on sharing learning material. "A Cloud based Smart Education System" [13], [14] enables the delivery and sharing of a variety of enhanced educational content managed in the cloud in a common, compatible, file format. This system also provides trainees with personalized learning content by analyzing their preferences, learning styles, and content usage patterns. In addition, a security system is provided for controlling data access and encryption in the cloud. NEC is also providing "Smart Education" cloud system [15] to solve the issues that arise when introducing e-education; learning support, teachers support, school affairs support, and $\mathrm{PC} /$ tablet management. These related systems offer total educational support system from sharing learning material or learning management to classroom environment management. This means that they are cumbersome systems that tend to be costly. On the other hand, our approach simply focuses on adapting the original digital learning material to the smart education environment. Thus making it light weight and comparatively cheap. We are not focusing on a heavy weight leaning management system. We expect this to make the obstacles to introducing Smart Education System into real education fields lower than other related systems. In addition, we focus on an application framework aiming for extensibility improvement of Smart Education System. As e-learning standard, SCORM [16] that stands for Sharable Content Object Reference Model has been proposed. How- 
ever, this standard focuses on heavy weight leaning management systems. This issue is also original point comparing to the existed work.

Some application frameworks for education relating system have been proposed. For example, Murugananthan proposed an application framework for educational data mining towards automated learning system [17]. The purpose of this work is to prepare an automated learning system in education support system to accomplish the appropriate learning content management system to the learners. Chunling proposed the Ruby On Rails based application framework for a college English Learning Management System, which enables us to promote the development of individualized study methods [18]. Dalmon introduced an application framework that implements a generic model for intelligent tutor authoring tools [19]. Intelligent tutor authoring tools provide many features that improve learning and teaching experiences. According to this application framework, teachers can author intelligent tutored assignments without programming. These related studies are intended to realize learning system that fitted a student and a teacher. Therefore, the purpose of these application frameworks is to change learning system easily according to the activity of learners or teachers. On the other hand, our proposed SES Framework is intended to realize extensibility of Smart Education System that can retrieve multi-aspect information concerning to a technical term embedded in the original digital learning material and display it on multi-screen devices. Therefore, the purpose of our proposed application framework is to change learning system easily according to the original digital learning material. That is the different point comparing to the relating system. We could say from the different point that the usefulness of our proposed application framework is to enable us to use a lot of original digital learning material without modification.

The automatic dictionary generation system [20] and the domain classification method for the automatic glossary generation system [21] have been proposed as research activities related to the learning support system for a technical term embedded in the digital learning material. The goal of these existing studies is to organize candidates of explanation information about target technical terms after gathering related information from the Internet using HTML construction analysis or text analysis. Much like in our study, the goal is to help users to understand technical terms. However, our study tries to learn technical terms described in digital learning material, by not only watching text information such as web pages but video information as well. We also try to utilize this system for the cloud based Smart Education System. These points are different with the related work.

\section{Requirements and Basic Idea}

\subsection{Requirements}

We extracted three requirements of Smart Education System

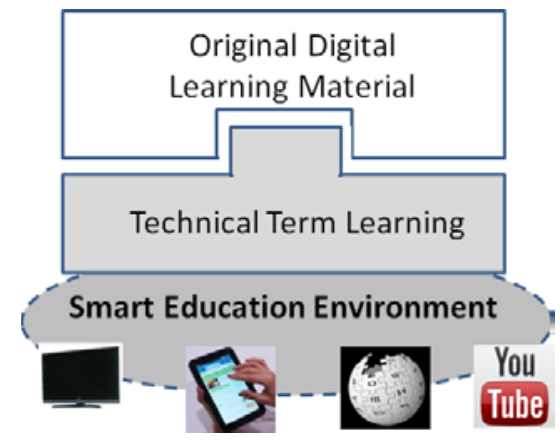

Fig. 2 Transforming model

and its framework from the viewpoint of a teaching staff, digital learning material providers, and trainees. The objective of our study is to establish Smart Education System that has the operability and the extensibility. The operability means that we should reduce the load on teaching staff such as setting server or network environment (Requirement 1). The extensibility means that we should adapt many kinds of original digital learning material with minimum modification (Requirement 2). We also defined Smart Education System as the mechanism that enables us to gather multiaspect information concerning to a technical term embedded in the original digital learning material automatically and to see such multi-aspect information on multi-screen devices according to user's operation (Requirement 3 ). Requirement 1 is for a teaching staff, Requirement 2 is for digital learning material providers, and Requirement 3 is for trainees. The requirement definitions are listed in the bellow.

- Requirement 1: Easy Smart Education System environment installation into the real education field.

- Requirement 2: Do not affect the original digital learning material and Smart Education System in case of changing the target digital learning material. For example, in case of utilizing Wikibooks as the original digital learning material, Wikibooks contents should not be modified. For example, even if Smart Education System needs to be modified to change the digital learning material, influenced part should be restricted and total amount of modifications should be slight.

- Requirement 3: Viewing of multi-aspect information coming from social media on the smart education environment including mobile devices or electronic black boards without depending on an information retrieval skill.

\subsection{Transforming Model}

Figure 2 shows Transforming Model that enables the migration of the original digital learning material to the smart education environment. The goal of this model is not to transform the original digital learning material in its entirety into the material for the smart education environment, but to transform only the desired technical terms into the material for the smart education environment. The technical 


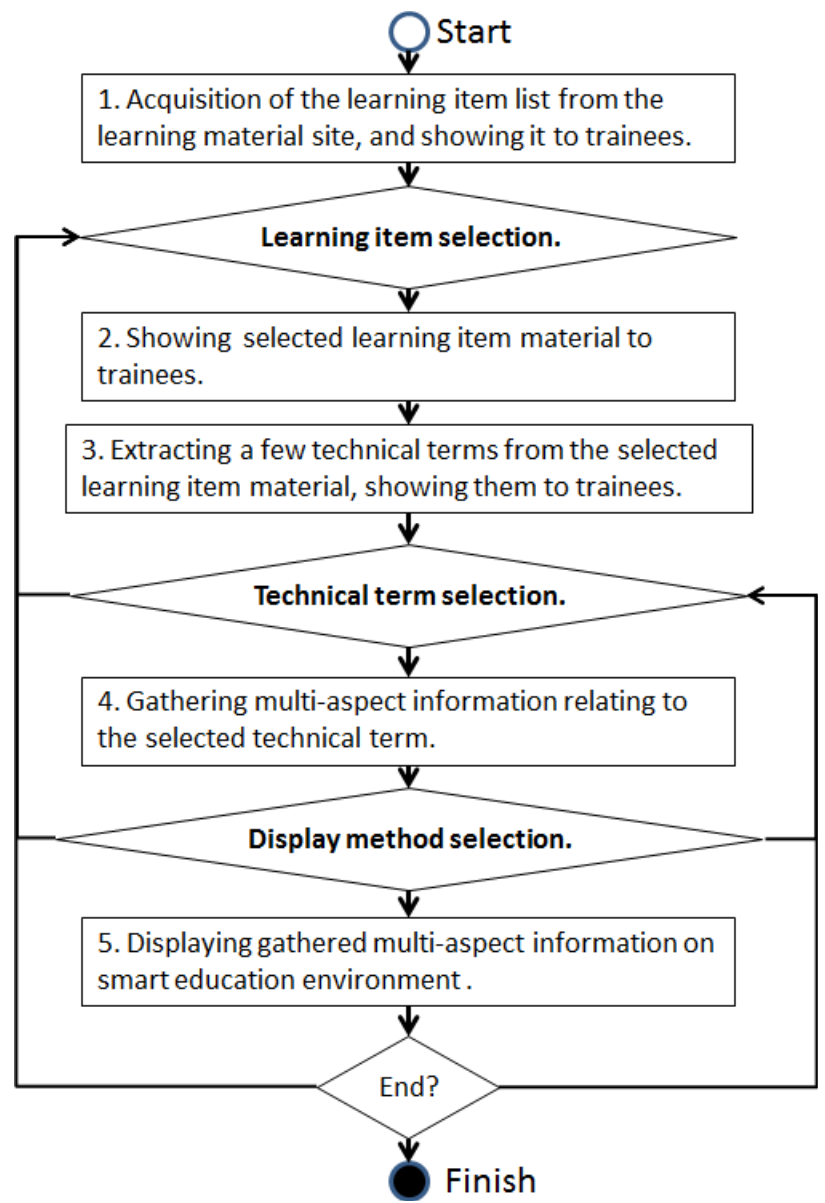

Fig. 3 Three-step operation flow

term learning on the smart education environment can be plugged into the original digital learning material as shown in Fig. 2. In this way, the original digital learning material and the technical term learning on smart education environment will be combined, then provided to trainees.

This plugged-in model makes it possible for the digital learning material providers to migrate the original digital learning material to one for the smart education environment without modifying the original digital learning material (Requirement 2).

\subsection{Three-Step Selection Flow}

Figure 3 shows an operation flow of Smart Education System from the viewpoint of trainees. In Fig. 3, $\square$ represents a process executed by the system and $\diamond$ represents an operation executed by trainees.

- 1. Acquisition of the learning item list from the learning material site, and showing it to trainees: In case of general Web sites, if information items, which should be displayed, are varied, it is popular to use a tab to classify item's category. Our system also provides the capability for trainees to select a tab to change the category of learning items. After selecting one of the learn- ing items, the next process begins (first step selection).

- 2. Showing selected learning item material to trainees: Trainees learn the selected learning item by viewing the selected learning material; text information, figures, tables, and videos.

- 3. Extracting several technical terms from the selected learning item material, showing them to trainees: If the selected learning item material does not include text information, Meta information described in text must be provided for the selected learning item material. Trainees select one of technical terms displayed on the screen to check detail information. Then, the next process begins (second step selection). Trainees can select the other learning item material instead of selecting one of technical terms. It would be better for us to extract appropriate technical terms from digital learning materials. Appropriate technical terms that trainees should learn in a digital learning material might differ according to each learner's learning context. In order to realize an appropriate technical terms selection mechanism depending on each trainee's learning context, we need to establish an advanced personalized mechanism using the context-aware technology. We also need to evaluate it independently, so that we think it should be another research topic. Therefore, we decided to extract and show same several technical terms to all trainees without using an advanced personalized mechanism. If we could extract and show comprehensive several technical terms, trainees could choose some of them according to their interests. We thought that this kind of user-oriented selection method could be more practical rather than the system-oriented selection method because we cannot develop perfect context aware systems. The detail method we proposed will be shown in Sect. 5.1.

- 4. Gathering multi-aspect information relating to the selected technical term: Outline information, social videos, tweets, and related book or product information concerning to the selected technical term will be gathered from social media as multi-aspect information. Trainees will order how the gathered information shall be displayed on the smart education environment. Then, the next process begins (third step selection). Trainees can select the other technical term or the other learning item material instead of ordering to show the gathered information on smart education environment.

- 5. Displaying gathered multi-aspect information on smart education environment: Trainees can order to display gathered multi-aspect information on the smart education environment. Trainees can select the other technical terms or the other learning item materials before terminating this system.

In this way, the original digital learning material can be applied for Smart Education System without alteration. From the viewpoint of trainees, we can say this Three-step Se- 


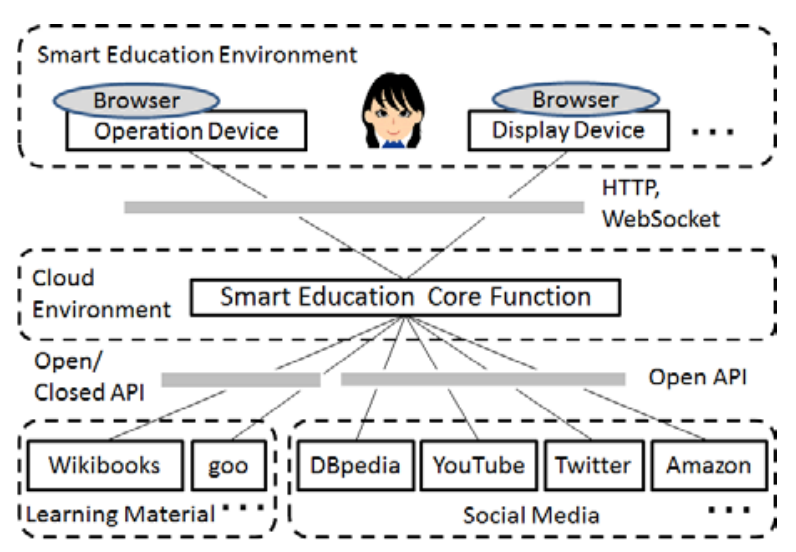

Fig. 4 System architecture

lection Flow that is the combination of learning item selection, technical term selection, and display method selection. These simple operations enable trainees to see multi-aspect information utilizing social media concerning the chosen technical term on the smart education environment (Requirement 3).

\section{Overview of SES Framework}

\subsection{System Architecture}

This system features three layers of architecture shown in Fig. 4. The middle layer is Smart Education Core Function run on the cloud-computing environment. The upper layer is the smart education environment existing in real learning fields such as classrooms in schools. Trainee devices in the smart education environment consist of an operation device that is mostly operated by a trainee and display devices used to see social videos, and so on. We suppose that the operation device is a tablet computer owned by each trainee and the display devices are the other computers like electronic black boards or the other mobile devices. The bottom layer is the Internet environment that includes the original digital learning material and many kinds of social media like DBpedia, YouTube, and so on.

The main feature of this system architecture is that Smart Education Core Function performs triple mashup due to Service-Oriented Architecture. The target of the first mashup is the original digital learning material. The first mashup realizes the use of the open or closed application interface (API) adapted to the local or public digital learning material site. The target of the second mashup is the external social media service. The second mashup is for gathering the multi-aspect information using the Open API. For example, the external social media services are DBpedia, YouTube, Twitter and Amazon. The target of the third mashup is a set of trainee's devices. The protocol between Smart Education Core Function and each trainee's device is HTTP and WebSocket [22], so that combinations among heterogeneous trainee's devices can be available just by installing the browser on to each device. In this way,

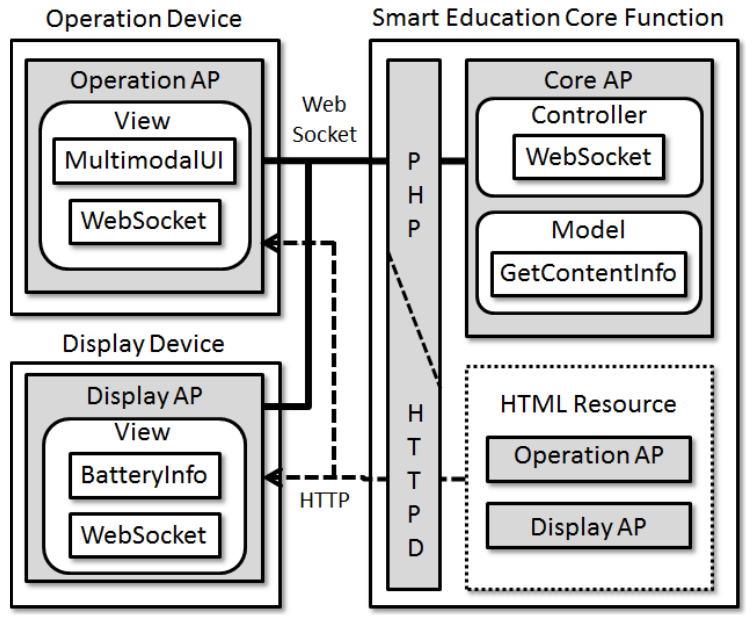

Fig. 5 SES framework

Smart Education Core Function allows trainees to operate the smart education environment consisting of heterogeneous devices. In this way, this triple mashup mechanism has an advantage of system configuration flexibility not only for the target digital learning material or social media but also for the smart education environment.

\subsection{SES Framework}

Figure 5 shows SES Framework. Screen devices operated by trainees are classified into an operation device and display devices. On Smart Education Core Function, core application (Core AP) as well as HTML resources including JavaScript for the operation device and the display devices (Operation AP and Display AP, respectively) has been arranged.

SES Framework is derived from MVC pattern that can be applied to a wide range of applications on Web services. A Controller function and a Model function have been assigned to Core AP. They are implemented by PHP. A View function has been assigned to Operation AP and Display AP. They are implemented by HTML5 and JavaScript.

The Controller of Core AP includes WebSocket class library to communicate with Operation AP or Display AP by exchanging a message command with identification number. In SES Framework, we used php-websocket-server 2.1.0 [23] as WebSocket class library for Web servers. The Model of Core AP has GetContentInfo class library to obtain the original digital learning material or relating information of that from external Web services. A part of Methods of GetContentInfo class is shown on Table 1. The Controller of Core AP calls methods of GetContentInfo class to retrieve information from external social media. The Controller of Core AP sends the View of Display AP a message command with identification number to display information from external social media according to a trainee operation via the View of Operation AP.

The operation device and the display devices allow HTTP access to Smart Education Core Function to obtain 
Table 1 GetcontentInfo class method example

\begin{tabular}{|c|c|}
\hline Method Example & Outline \\
\hline get_material & $\begin{array}{l}\text { To collect original digital learning } \\
\text { material like Wikibooks. }\end{array}$ \\
\hline get_keyphrase & $\begin{array}{l}\text { To extract key phrases from selected } \\
\text { learning item. }\end{array}$ \\
\hline get_movie_thumnail & $\begin{array}{l}\text { To prepare movie thumbnails } \\
\text { connecting to YouTube. }\end{array}$ \\
\hline get_dbpedia & $\begin{array}{l}\text { To collect key word outline information } \\
\text { from DBpedia. }\end{array}$ \\
\hline get_twitter_info & To collect tweets from Twitter. \\
\hline
\end{tabular}

HTML resources with JavaScript, such as Operation AP and Display AP, respectively, via each browser. The View of Operation AP or Display AP includes WebSocket class prepared by a browser to communicate with the Controller of Core AP by exchanging a message command with identification number. The View of Operation AP has also a multimodal user interface (MultimodalUI) which can be used for intuitive user interfaces against a trainee like a drag and drop operation by a touch sensor, a motion operation by an acceleration sensor or a voice operation by speech recognition. The view of Display AP has also an ability to detect battery information (BatteryInfo) besides information displaying functionality according to message commands from the Controller. The display devices might be battery-operated devices in some cases. Then, we implemented the function to notify Operation AP regularly about remaining battery quantity via WebSocket based on Battery Status API [24] by JavaScript.

\section{Implementation Example Using SES Framework}

We implemented a smart education prototype system as an example using SES Framework. In this implementation, we chose Wikibooks as the target digital learning material. In Wikibooks, we selected a subject of science for Japanese elementary school from 3rd grade to 6th grade. The prototype system specification is shown in Fig. 6. In terms of Smart Education Core Function, it was constructed in two ways. One was to set up Smart Education Core Function on the local area network of our laboratories. The other was to set up Smart Education Core Function on Amazon Web Services (AWS) [25] cloud system. We confirmed that both ways were applicable for prototype system evaluation.

\subsection{Process Flow of the Prototype System}

Prototype process flow is explained according to the operation flow described in Fig. 3.

- 1. Acquisition of the learning item list from the learning material site, and showing it to trainees: The Model of Core AP retrieves subject contents list of Wikibooks according to parsing the target Wikibooks

\begin{tabular}{|c|c|c|}
\hline $\begin{array}{l}\text { Amazon Web } \\
\text { Services }\end{array}$ & Operation Device & Display Device \\
\hline $\begin{array}{l}\text { - Linux CentOS 6.4, } \\
\text { Apache 2.2.15, } \\
\text { PHP 5.3.3, } \\
\text { WebSocketServer } \\
2.1 .0\end{array}$ & $\begin{array}{l}\text { - Windows Tablet, } \\
\text { Win8 32bit, } \\
\text { Chrome } 18.0 \\
\text {-iPad Mini, } \\
\text { iOS 7.0.2, Safari }\end{array}$ & $\begin{array}{l}\text { - Windows PC, } \\
\text { Chrome } 18.0 \\
\text { - iPod Touch, } \\
\text { iOS 7.0.3, Safari } \\
\text { - iPad Mini, } \\
\text { iOS 7.0.2, Safari }\end{array}$ \\
\hline
\end{tabular}

Fig. 6 Prototype system specification

HTML pages. Retrieved subject contents list will be sent to the View of Operation AP through WebSocket after reformatting to XML, and then displayed as tab images classified by the item's category like Science 3rd Grade, Science 4th Grade, and so on.

- 2. Showing selected learning item material to trainees: Selected subject contents will be displayed by the View of Operation AP after adding HTML tags according to media type.

- 3. Extracting technical terms from the selected learning item material, showing them to trainees: We chose to offer the same several technical terms to trainees using the key phrase extraction provided by Yahoo! Developer Network [26]. This functionality has been implemented in the method named get_keyphrase in GetContentInfo class library (Table 1). If the number of extracted technical terms is low, there might be a miss match between the extracted technical terms and the trainee is interested. In the case of Encyclopædia Britannica that is a famous English encyclopedia, 500,000 keywords are described in approximately 40 million words [27]. The keyword incidence becomes $1.2 \%$ from these statistics information. On the other hand, we investigated the volume of the subject of science for Japanese elementary school from 3rd grade to 6th grade on Wikibooks that was our target learning material in this paper. In the case of Wikibooks, the subject has been divided into small units. The average volume of small unit is about 750 words for readability. Therefore, when we apply the keyword incidence (1.2\%) of Encyclopædia Britannica to the small unit of Wikibooks, the number of keywords becomes nine $(750 * 0.012)$. We also considered the psychological side that five-nine alternatives should be shown by the art of choosing [28] and display size of a tablet computer in the sense of visibility and operability. Therefore, we decided to extract exactly nine technical terms per each small unit. Of course, when we intend for the digital learning materials except Wikibooks, we need to consider dividing it into small unit that has about 750 words. If we could have technical terms more than nine from the key phrase extraction, we would select top nine ones according to the score information returned by the key phrase extraction. We do not care the algorithm of the key phrase extraction, so that we can easily change the other advanced key phrase ex- 
traction algorithm just after customizing get_keyphrase method.

- 4. Gathering multi-aspect information relating to the selected technical term: The Model of Core AP collects the multi-aspect information by searching for the technical term, a keyword selected by a trainee, through Open API of DBpedia [29], YouTube [30], Twitter [31], and Amazon [32]. GetContentInfo is the only part that has been implemented as part of Open API. Therefore, even if these external social media services will be upgraded in future, it will be enough to customize only that part of GetContentInfo. The same manner can be said in the case of adding a new external social media.

- 5. Displaying gathered multi-aspect information on smart education environment: The Controller of Core AP distributes the gathered multi-aspect information to the View of Operation AP or Display AP, which will

\begin{tabular}{|l|l|l|l|}
\hline $\begin{array}{l}\text { Output } \\
\text { Targets }\end{array}$ & $\begin{array}{l}\text { Same } \\
\text { Tab } \\
\text { Social Media }\end{array}$ & $\begin{array}{l}\text { New } \\
\text { Tab }\end{array}$ & $\begin{array}{l}\text { Different } \\
\text { Screen } \\
\text { Devices }\end{array}$ \\
\hline $\begin{array}{l}\text { DBpedia, Twitter } \\
\text { (Text) }\end{array}$ & 0 & - & - \\
\hline $\begin{array}{l}\text { Amazon, Yahoo, } \\
\text { Facebook } \\
\text { (Text, Pictures) }\end{array}$ & - & 0 & - \\
\hline YouTube(Movies) & - & - & 0 \\
\hline
\end{tabular}

Fig. 7 Output destination decision be shown on the same tab or a new tab of the operation device browser, or different display devices' browsers. Output destination decision of the multi-aspect information depends on its media type, like texts, pictures, and movies, because of the viewpoint of the user's visibility (Fig. 7).

\subsection{Practical Implementation}

Figure 8 shows the user interface example of the operation device. In this user interface, we can scroll the screen upand-down like (a), (b), and (c) in Fig. 8.

- (a) to middle part of (b): The Subject categories are displayed on the top of the screen. Then, we can select the tab like Science 3rd Grade, Science 4th Grade, and so on. In terms of Wikibooks subject contents extraction mechanism, we retrieved them as XML format utilizing PHP function that is simplexml_load_file(). If the one of subject contents is selected, only the selected subject content will be displayed on the operation device. In the case of Fig. 8, “へチマ” (sponge cucumber) has been selected. We used Boilerpipe [33] as a parser function to extract only subject content from a Wikibooks page. Boilerpipe has the mechanism that judges subject contents or another parts like advertisements based on a probability model against the feature of word appearance [34]. Boilerpipe is offered as a Web API or Java library. We implemented the parser function as a Java program using Boilerpipe Java li-

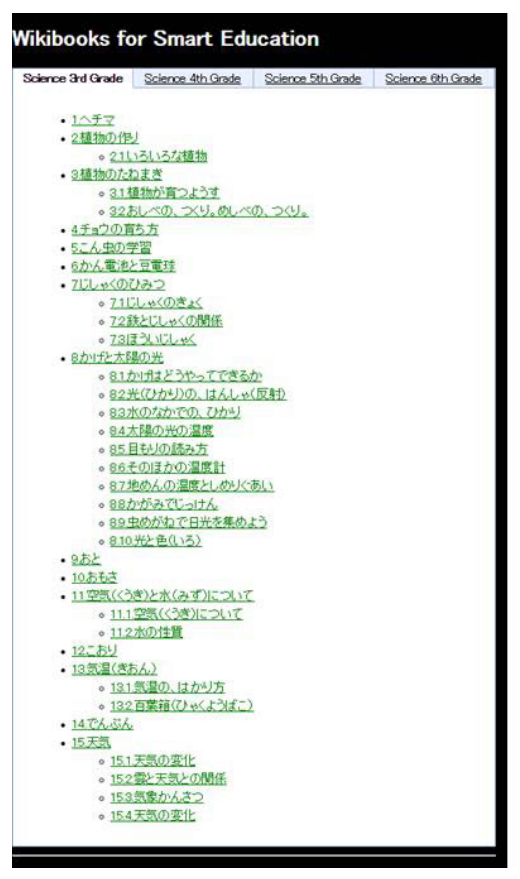

(a)
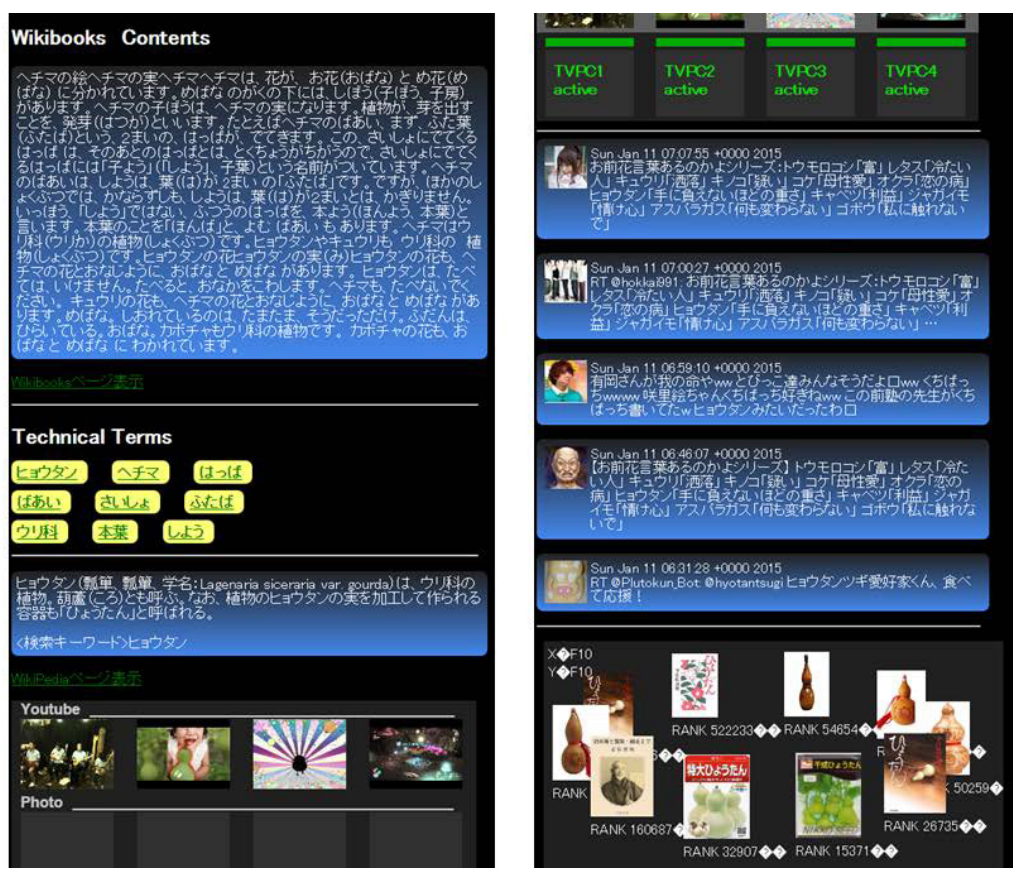

(b) (c)

Fig. 8 Operation device user interface for wikibooks 


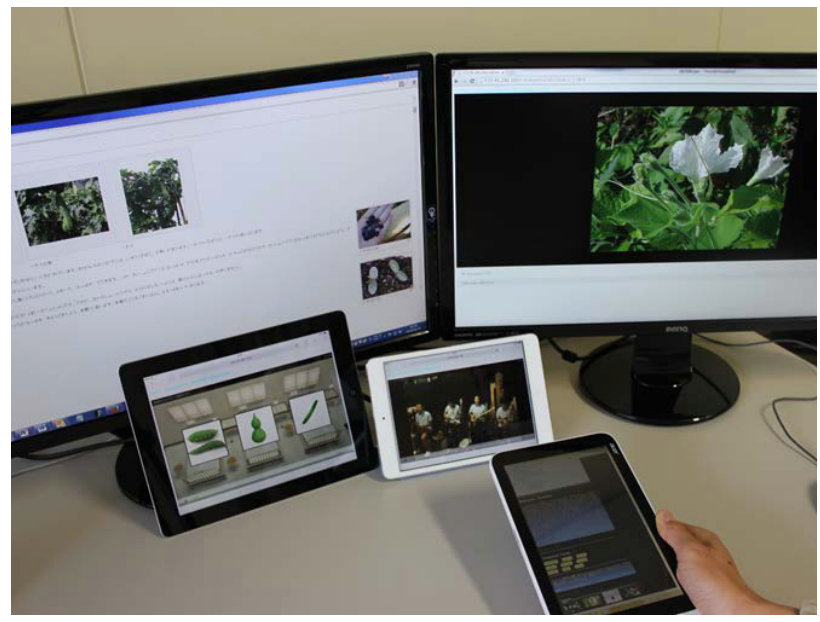

Fig.9 Smart education environment for wikibooks

brary. Under the subject contents, nine technical terms are displayed.

- Bottom part of (b) to upper part of (c): When one of technical terms is selected, a brief outline is displayed as text information. In the case of Fig. 8, the technical term that is a “ヒョウタン” (gourd) has been selected. Related YouTube video's thumbnails are shown under the outline information. TVPC1-4 means the available display devices to show YouTube videos. YouTube videos will be shown on display devices by dragging $\&$ dropping thumbnails to the TVPC1-4 area, shaking the tablet computer, or voice commands.

- Middle part of (c) to the end: Tweet information and books \& products information associated with the selected technical term are displayed. Tapping thumbnail of books \& products will make the browser show a webpage that provides more detail information about it. Tweet information can be used for sharing learning information among trainees or teachers.

Figure 9 shows the usage scene of this system. The lower right tablet computer (operation device) makes it possible to show an original Wikibooks contents page, DBpedia page as well as the YouTube videos. Information distributed on the smart education environment, like in Fig. 9, can be changed in a moment when the order, either by tapping or speaking, is given. Using this smart education environment, trainees can learn unknown technical terms through multi-aspect information one by one. We also confirmed that we did not have to modify original Wikibooks contents.

\section{Evaluation}

In this section, we evaluate each requirement defined in Sect.3.1. We did the field test for evaluating the requirement of a teaching staff. In order to evaluate requirements of digital learning material providers, we did the system modification case study that is replacing the target digital learning material of Smart Education System. We also did the

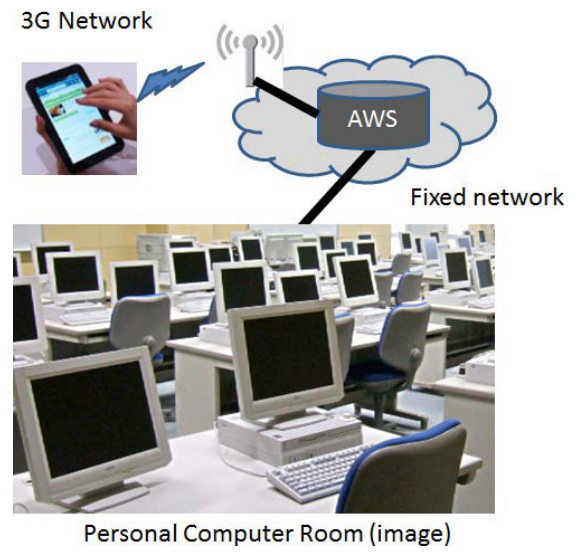

Fig. 10 Nakagoto high school experimental environment

trainee's point of view evaluation for validating the requirement of trainees.

\subsection{Field Experiment}

We had a real world field experiment at Nagasaki prefectural Nakagoto High School on 12 September 2013 (Fig. 10). The security policy of Nakagoto High School prohibited a hand device from connecting with the internal network. Therefore, we used a tablet computer connected with $3 \mathrm{G}$ network and personal computers at the multi-media room of Nakagoto High School connected with the Internet via fixed network. We demonstrated that we could distribute associated social videos onto the personal computers at the multi-media room in Nakagoto High School by operating the tablet computer. The only advance preparation required was to input the URL of Smart Education Core Function located in Amazon Web Services, into the pre-installed browsers of the tablet computer and the personal computers of Nakagoto High School. We did not need to modify the firewall configuration of Nakagoto High School, nor did we need to change the settings of the personal computers of Nakagoto High School. This result satisfies Requirement 1.

After demonstration, we got impression essays written in a natural language from all students who watched our demonstration. We confirmed that students more than $90 \%$ had a positive opinion from those impression essays objectively. Especially, the multi-aspect information to learn unknown technical terms or the multimodal user interface had a good reputation.

\subsection{System Modification Case Study}

In this case study, we tried to change the target digital learning material from Wikibooks to news articles provided by "goo" [35], a Japanese search engine site. News articles include unknown keywords sometimes, so that we considered that it would be suitable digital learning material for liberal arts education. Figure 11 shows the usage scene of the operation device after modification. The user interface image is almost same of the case of Wikibooks (Fig. 8). The top 

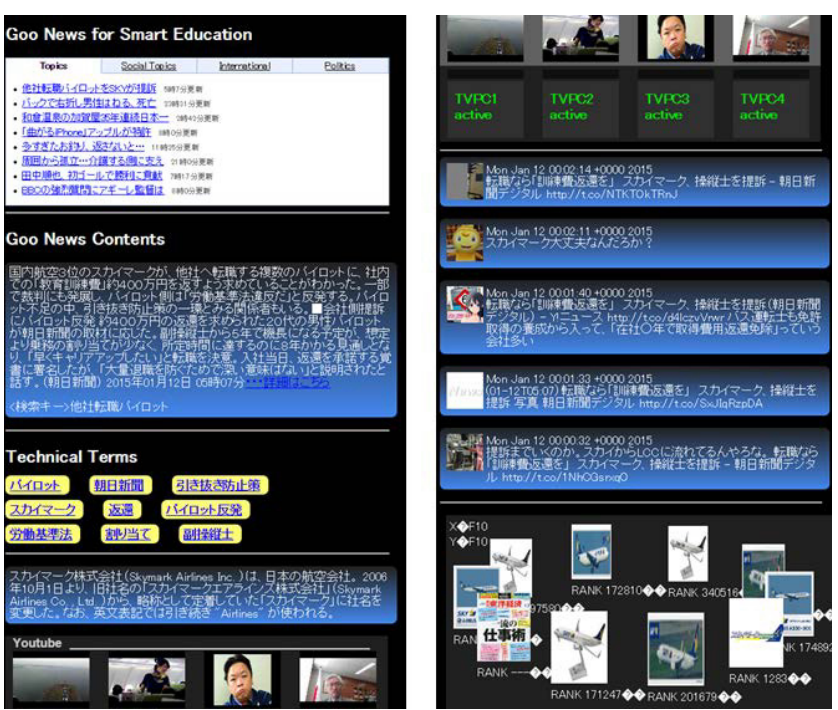

Fig. 11 Usage scene after modification

Table 2 Modification result for replacement

\begin{tabular}{|c|c|c|c|c|c|c|}
\hline Application & $\begin{array}{l}\text { Total } \\
\text { lines }\end{array}$ & Part & $\begin{array}{l}\text { Line Re- } \\
\text { moved }\end{array}$ & $\begin{array}{l}\text { Line } \\
\text { Changed }\end{array}$ & $\begin{array}{l}\text { Line } \\
\text { Added }\end{array}$ & $\begin{array}{l}\text { Total } \\
\text { Modifications }\end{array}$ \\
\hline \multirow{2}{*}{ Core AP } & \multirow{2}{*}{604} & Controller & 3 & 7 & 0 & 10 lines, $1.7 \%$ \\
\hline & & Model & 27 & 0 & 110 & 137 lines, $22.7 \%$ \\
\hline $\begin{array}{l}\text { Operation } \\
\text { AP }\end{array}$ & 895 & View & 57 & 9 & 12 & 78 lines, $8.7 \%$ \\
\hline $\begin{array}{l}\text { Display } \\
\text { AP }\end{array}$ & 108 & View & 0 & 0 & 0 & 0 lines, $0 \%$ \\
\hline Total & 1,607 & & 87 & 16 & 122 & 225 lines, $14.0 \%$ \\
\hline
\end{tabular}

tab window at the upper left of Fig. 11 indicates news article titles instead of Wilibooks subject contents. We also confirmed that we could operate it in the same way of Wilibooks case.

Table 2 shows the modification result applied to this replacement experiment. From Table 2, we can see that the modification part has been almost concentrated in the Model of Core AP, GetContentInfo class library. The main modification reason for the Model of Core AP is to handle RSS (Rich Site Summary) provided "goo" to retrieve news articles. The total amount of modifications is less than 25\% within Core AP, also less than $15 \%$ against total system code amount. This result indicates the good evidence that SES framework works well for reducing the modification of Smart Education System for changing the digital learning material (Requirement 2). Especially, the result of influenced part restriction within GetContentInfo class library contributes the system extensibility. On the other hand, the original digital learning material itself did not need to be modified in the cases, Wikibooks and goo.
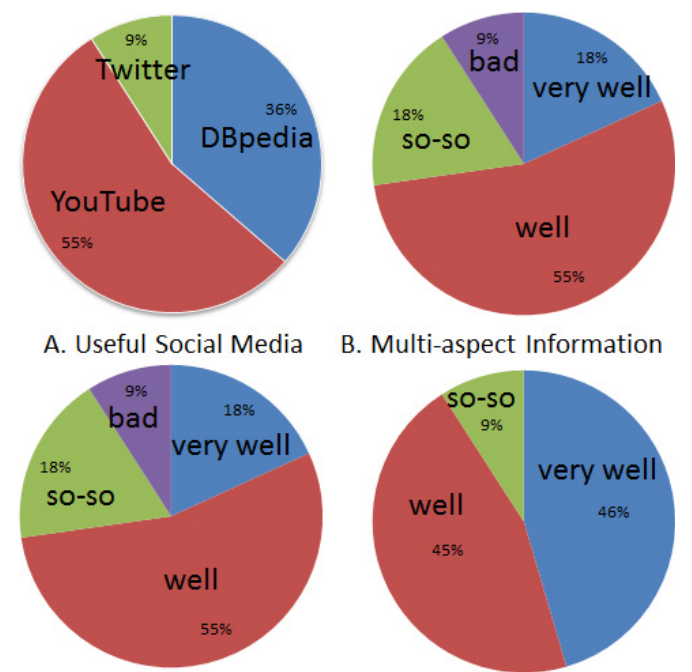

B. Multi-aspect Information

C. Smart Education Environment

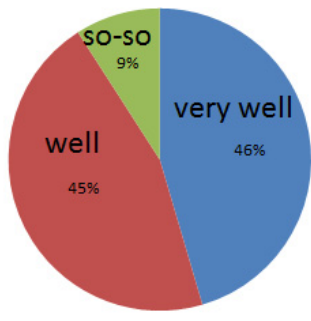

D. Total Effectiveness

Fig. 12 User evaluation results

\subsection{Validating Trainees Requirement}

We evaluated the learning effect between Smart Education System and other methods [6]. Smart Education System enables trainees to see the multi-aspect information distributed on the smart education environment without special operations. The multi-aspect information can be gathered from social media using a technical term extracted automatically from the digital learning material. Therefore, we evaluated the effectiveness of the automatic multi-aspect information distribution in the smart education environment. We selected 29 news articles at random distributed from Yahoo! News on 15th, 16th April 2014. We asked 11 people (men: 8, women: 3 ) who are from 18 years old to 22 years old university students as examinees. After using Smart Education System, we asked them the following questions.

- A: Which social media is the most useful as multiaspect information such as DBpedia, YouTube, Twitter, and Amazon?

- B: Is it useful for you to know your selected technical term by seeing the multi-aspect information in comparison with seeing the single-aspect information?

- C: Is it useful for you to know your selected technical term by seeing the multi-aspect information on the smart education environment?

- D: Is Smart Education System good enough for trainees who have different abilities or accessibilities to retrieve information?

We asked the examinees to answer five-level evaluation, "very well", "well", "so-so", "bad", and "very bad". Figure 12 shows the evaluation result.

- A: Video information from YouTube was considered more useful than text information from DBpedia.

- B: Against the question about usefulness of the multiaspect information, $73 \%$ examinees answered that it 
was very well or well.

- C: Against the question about usefulness of the smart education environment, $73 \%$ examinees answered that it was very well or well.

- D: Against the question about usefulness of the automatic information retrieving mechanism, 91\% examinees answered that it was very well or well. Especially, $46 \%$ examinees answered that it was very well.

According to these results, we have confirmed the effectiveness of showing the multi-aspect information in comparison with showing the single-aspect information. We have also confirmed the effectiveness of using the smart education environment and the automatic multi-aspect information retrieving, which gets rid of a difference of information searching skill.

\section{Discussion}

We confirmed that we could provide the smart education environment based on tablet computers and the other computers located in the real education field utilizing the commercial cloud computing service. Moreover, the only preparation is simply to input the special URL that indicates the cloud computing server address installed Smart Education Core Function into each computer's browser. This means, from the view point of the real education field-teaching staff, it is enough only to prepare tablet computers and/or other computers, which have already had their browsers, installed in advance. This satisfies the Requirement 1.

Through the practical implementation (Sect.5.2), we have confirmed that we did not have to modify original Wikibooks contents itself. This means that we could satisfy the Requirement 2 . In the system modification case study mentioned in previous section, we also confirmed that we could extend Smart Education System with minimum modification thanks to SES Framework that is relating to Requirement 2. We need to have only one assumption that the target learning material needs to have text information, because the system retrieves the multi-aspect information by searching the technical term embedded in the text information of the target learning material. However, even if in the case that the target learning material does not have the text information, learning material providers can add the text information as Meta information later. That is the reason why this assumption will not be a critical one.

In the viewpoint of trainees, we have confirmed the effectiveness of showing the multi-aspect information, using the smart education environment, and the automatic multiaspect information retrieving without depending on an information retrieval skill through the trainee's usage experiment. These results are relating to Requirement 3. However, our final goal is to improve the understanding of trainees with different degree of achievement. In order to achieve this goal, we need to introduce a learning context-aware technology and a long-term experiment in a real educational front. Those will be our future work.
On the other hand, we made the reliability of contents extracted from social media out of scope in this paper. In order to introduce this proposed system in the real education filed, we mandatory need to handle this issue. However, contents filter techniques have been already established to avoid harmful contents as commercial services so that we could combine these services with our system.

\section{Conclusion}

This paper proposed an application framework, SES Framework, for Smart Education System utilizing mobile devices and the cloud systems. We examined Smart Education System at the real education field. We evaluated SES framework according to the practical implementation and the case study of changing the target learning material. We also evaluated it in the viewpoint of trainees.

Through these experiments, we confirmed that there was no impact to the real education field to use Smart Education System thanks to the cloud-based system. We confirmed that we could utilize the original digital learning material without modification, reduce the modification even if Smart Education System needed to be modified to change the digital learning material, and educe different aspects related to unknown technical terms. We also confirmed the effectiveness of showing the multi-aspect information, using the smart education environment, and the automatic multiaspect information retrieving. In these results, we could say that all requirements of Smart Education System and its framework have been satisfied.

In our future work, we will add the contents filter function and the learning context-aware technology to our system. We will also execute a long-term experiment in a real educational front like an elementary school attached to our university. Then, we will get useful feedback to enhance our system to be more practical one.

\section{Acknowledgments}

This work was supported by JSPS KAKENHI Grant Number $15 \mathrm{H} 02783$.

\section{References}

[1] Moodle, https://moodle.org/, (accessed 2016-03-08).

[2] Future School Promotion Project, Ministry of Internal Affairs and Communications (MIC), JAPAN, April 2013, http://www.itu.int/ ITU-D/finance/work-cost-tariffs/events/tariff-seminars/Japan-13/ documents/Sess5-2_FutureSchool_Kobayashi.pdf, (accessed 201603-08).

[3] T. Kobayashi, "A Proposal of Smart TV System focused on Findability," 2013 IEEE 2nd Global Conference on Consumer Electronics (GCCE), pp.507-508, 2013.

[4] T. Kobayashi, "Information Orchestration System for Closing the Information Retrieval Capability Gap," Proc. 2014 IEEE 38th Annual International Computers, Software and Applications Conference (COMPSAC2014), pp.644-645, 2014.

[5] T. Kobayashi, "An Application Framework for Trend Surfing System based on Multi-aspect, Multi-screen and Multimodal User Interface," Journal of Information Processing, vol.23, no.6, pp.795-803, 
2015.

[6] T. Kobayashi, "MSaaS-type Smart Education Support System using Social Media," Proc. 3rd IEEE International Conference on Mobile Cloud Computing, Services, and Engineering (IEEE Mobile Cloud 2015), pp.119-127, 2015.

[7] T. Kobayashi, "An Application Framework for Smart Education System on Mobile and Cloud Systems," Proc. 2016 IEEE International Conference on Teaching and Learning in Education (ICTLE'16), pp.278-683, 2016.

[8] Wikibooks, http://www.wikibooks.org/

[9] P. Pocatilu, F. Alecu, and M. Vetrici, "Using Cloud Computing for E-learning Systems," Proceedings of the 8th WSEAS international conference on Data networks, communications, computers, pp.5459, Nov. 2009.

[10] U.J. Bora and M. Ahmed, "E-Learning using Cloud Computing," International Journal of Science and Mod-ern Engineering, vol.1, no.2, pp.9-12, 2013.

[11] M.A.H. Masud and X. Huang, "An E-learning System Architecture based on Cloud Compu-ting," World Academy of Science, Engineering and Technology, 62, pp.74-78, 2012.

[12] N. Sultan, "Cloud computing for education: A new dawn?," International Journal of Information Management, vol.30, no.2, pp.109-116, 2010.

[13] J.-S. Jeong, M. Kim, K.-H. Yoo, "A Cloud based Smart Education System for e-Learning Content Services," CES-CUBE 2013, ASTL, vol.25, pp.131-133, 2013.

[14] J.S. Jeong, J.O. Kim, D.H. Kim, S.O. Kwon, S.Y. Ju, J.W. Lee, C. Park, M.S. Lim, D.Y. Kim, R.H. Jang, J. Fiaidhi, and K.H. Yoo, "Contents Oriented Cloud Educational Systems," Proceedings of the ICCC 2012, pp.457-458, 2012.

[15] e-Education Cloud Smart Eduaction, NEC http://www.nec.com/en/ event/mwc/pdf/6.pdf, (accessed 2016-03-08).

[16] SCORM, https://www.adlnet.gov/adl-research/scorm/, (accessed 2016-11-03)

[17] V. Murugananthan and B.L. Shivakumar, "A Novel Application Framework for Educational Data Mining Towards Automated Learning System," Proc. International Conference on Intelligent Computing Applications, pp.148-152, 2014.

[18] C. Chunling, "Construction of the Individualized College English Learning Management System Using Ruby on Rails," Proc. International Conference on Service Science, pp.160-163, 2015.

[19] D.L. Dalmon, L.O. Brandão, G.M. Gomes, A.A.F. Brandão, and S. Isotani, "Work in progress: A generic model for interactivity-intense intelligent tutor authoring tools," Frontiers in Education Conference Proceedings, pp.1-2, 2012

[20] A. Fuji and T. Ishikawa, "Utilizing the World Wide Web as an encyclopedia: Extracting term descriptions from semi-structired texts," Proc. 38th Ammual Meeting of the Association for Computational Linguistics, pp.488-495, 2000.

[21] M. Kida, M. Tonoike, T. Utsuro, and S. Sato, "Domain Classification of Technical Terms Using the Web," Systems and Computers in Japan, vol.38, no.14, pp.11-19, 2007.

[22] The WebSocket API, http://www.w3.org/TR/2011/ WD-websockets-20110929/, (accessed 2016-03-08).

[23] php-websocket-server 2.1.0, https://github.com/memory-agape/ php-websocket-server, (accessed 2016-03-08).

[24] Battery Status API, http://www.w3.org/TR/battery-status/, (accessed 2016-03-08).

[25] Amazon web services, http://aws.amazon.com/, (accessed 2016-0308).

[26] Key phrase extraction Web API, http://developer.yahoo.co.jp/ webapi/jlp/keyphrase/v1/extract.html, (accessed 2016-03-08).

[27] Encyclopedia Britannica, https://www.britannica.com/, https://en.wikipedia.org/wiki/Encyclop\%C3\%A6dia_Britannica

[28] S. Iyengar, The Art of Choosing, Grand Central Publishing, 2011.

[29] DBpedia API, http://dbpedia.org/About, (accessed 2016-03-08).

[30] YouTube API, https://developers.google.com/youtube/ getting_started?hl=en, (accessed 2016-03-08).

[31] Twitter API, https://dev.twitter.com/, (accessed 2016-03-08).

[32] Amazon API, http://docs.aws.amazon.com/ AWSECommerceService/latest/DG/Welcome.html, (accessed 201603-08).

[33] Boilerpipe, http://boilerpipe-web.appspot.com/

[34] C. Kohlschütter, P. Fankhauser, and W. Nejdl, "Boilerplate Detection using Shallow Text Features," Proceeding WSDM '10 Proceedings of the third ACM international conference on Web search and data mining, pp.441-450, 2010.

[35] goo rss, http://www.goo.ne.jp/rss/, (accessed 2016-03-08).

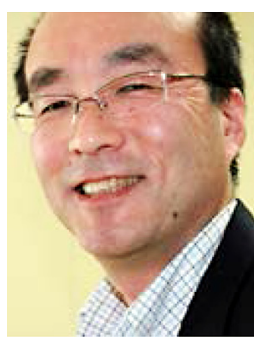

Toru Kobayashi is a professor at the Division of Electrical Engineering and Computer Science, Graduate School of Engineering, Nagasaki University. He received Ph.D. (2011) in engineering from the University of Electro-Communications. He has worked for NTT (1987-2013). He is a senior member of IEICE, a senior member of IPSJ, and a member of IEEE.

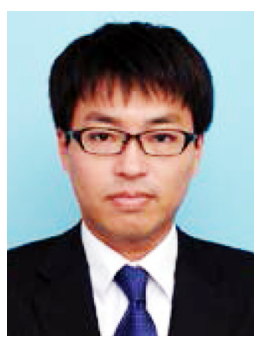

Kenichi Arai graduated from Shinshu University, Japan where he received his B.E., M.E., and Dr.E. degrees in 2004, 2006, and 2010, respectively. He is currently an assistant professor at the Division of Electrical Engineering and Computer Science, Graduate School of Engineering, Nagasaki University. $\mathrm{He}$ is a member of IEICE and a member of IPSJ.

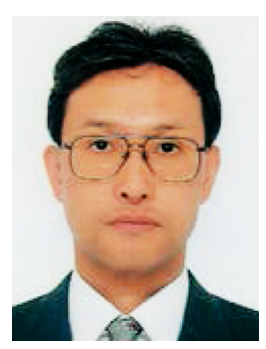

Hiroyuki Sato is an Associate Professor of the University of Tokyo. B.Sc, M.Sc, and D.Sc from the University of Tokyo in 1985, 1987, 1990, respectively. His interest lies in programming languages and information security. Kantara accredited assessor from 2015.

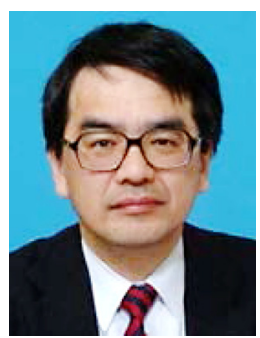

Shigeaki Tanimoto graduated from University of Tokushima, Japan where he received his B.E., M.E. and Dr. E. degrees in 1982, 1984 and 1997, respectively. He joined NTT Laboratories from 1984 to 2009, and he is currently Professor at Chiba Institute Technology. He is a senior member of IEICE, a senior member of IPSJ, and a member of IEEE. 


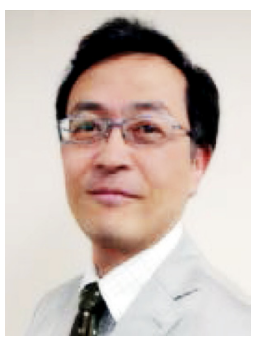

Atsushi Kanai received the B.S., M.S. and $\mathrm{Ph} . \mathrm{D}$ degrees from Tohoku University in 1980, 1982 and 2002 respectively. Since 1982, he had worked at NTT Laboratories. He is currently a professor of Applied Informatics at Faculty of Science and Engineering, Hosei University. He is a senior member of IEICE, a senior member of IPSJ, and a member of IEEE. 